\title{
The roles of epigallocatechin-3-gallate in the treatment of neuropathic pain: an update on preclinical in vivo studies and future perspectives
}

This article was published in the following Dove Press journal:

Drug Design, Development and Therapy

13 September 2017

Number of times this article has been viewed

\author{
Sabrina Bimonte ${ }^{1, *}$ \\ Marco Cascellal,* \\ Vincenzo Schiavone ${ }^{2}$ \\ Farrokh Mehrabi-Kermani ${ }^{3}$ \\ Arturo Cuomo' \\ 'Division of Anesthesia and Pain \\ Medicine, Istituto Nazionale Tumori - \\ IRCCS - "Fondazione G. Pascale", \\ Naples, Italy; ${ }^{2}$ Division of Anesthesia \\ and Intensive Care, Hospital "Pineta \\ Grande", Castel Volturno, Caserta, \\ Italy; ${ }^{3}$ Division of Neurosurgery, \\ Hospital "Pineta Grande", Castel \\ Volturno, Caserta, Italy \\ *These authors contributed equally \\ to this work
}

\begin{abstract}
Neuropathic pain (NP) is a complex and chronic disease caused by lesions or defects of the somatosensory nervous system. The treatments normally used for managing NP usually lack efficacy. Several animal models of NP have been engineered in order to understand the molecular mechanisms underlying NP and to find alternative molecules to use as new therapeutic agents. Preclinical in vivo studies identified the epigallocatechin-3-gallate (EGCG), a main active component of green tea (Camellia sinensis), as a possible therapeutic molecule for NP treatment due to its anti-inflammatory and antioxidant properties. Interestingly, it has been shown that EGCG reduced bone cancer pain. The purpose of this article is to discuss the potential use of EGCG for control and treatment of NP, by reviewing the preclinical studies reported in the literature and by shedding light on the potential schemes based on EGCG's application in clinical practices.
\end{abstract}

Keywords: epigallocatechin-3-gallate, EGCG, natural compound, neuropathic pain, animal models of neuropathic pain, cancer bone pain

\section{Introduction}

Neuropathic pain (NP) is a complex and chronic disorder caused by lesions or defects of the somatosensory system. ${ }^{1-3}$ Because NP can arise anywhere in the nervous system, it is commonly divided into three different types: 1) central NP (caused by defects of central nervous system [CNS]), 2) peripheral NP (caused by defects of peripheral nervous system [PNS]), and 3) mixed NP (due to alterations of PNS and CNS).

Central NP can arise from different disorders involving the brain or the spinal cord. Most frequent is the occurrence of peripheral NP which is a consequence of multiple disorders, such as neurotoxic chemicals, infections, metabolic diseases, mechanical trauma, and tumor invasion. ${ }^{4,5}$ Moreover, it is of note that iatrogenic pain syndromes are due to many cancer treatments or palliative care such as radiation therapy, chemotherapy, and surgery. ${ }^{6}$ For these reasons, NP dramatically affects the quality of life of patients.

Unfortunately, with the pharmacological approaches to treat NP, no encouraging results were obtained in patients suffering from NP. ${ }^{7}$ Thus, new alternative therapies have been proposed.

To understand the molecular mechanisms underlying NP to find new effective therapies as well as to bypass the problem of diverse etiology of NP, several animal models have been generated. ${ }^{8}$ Models largely used to study peripheral NP were obtained by ligation-mediated peripheral nerve injury, as schematized in Figure 1. Moreover, 


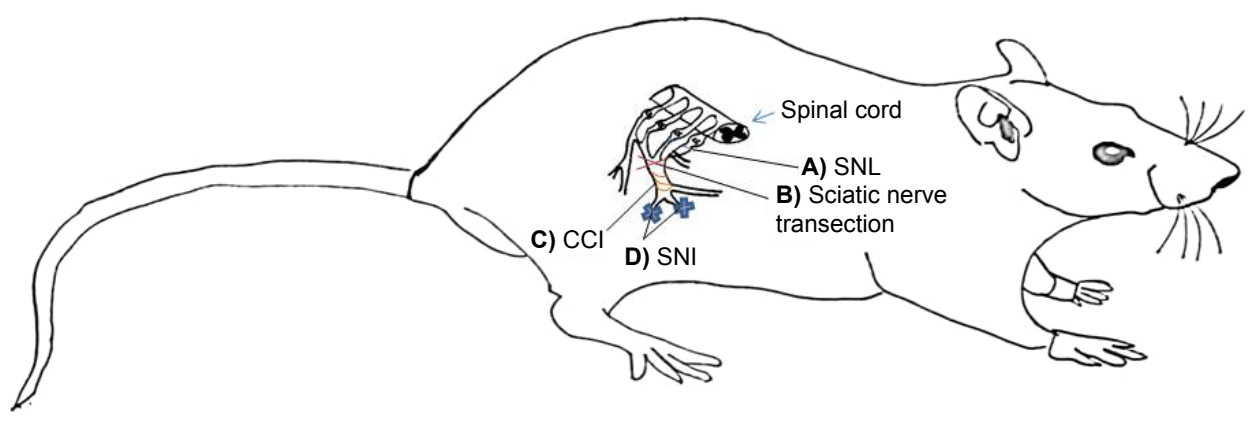

Figure I Schematic representation of the major animal models of nerve injury.

Notes: A) SNL obtained by ligations around L5 and L6; B) Sciatic nerve transection; C) CCl obtained by ligations around the sciatic nerve; D) SNI obtained by transection of the tibial and the peroneal branches without affecting the sural nerve.

Abbreviations: $\mathrm{CCl}$, chronic constriction injury; SNI, spared nerve injury; SNL, spinal nerve ligation.

additional models for NP induced by different agents and/or causes (chemotherapeutic agents, HIV, ethanol, and diabetes) have also been designed (see the study by Jaggi et $\mathrm{al}^{8}$ for a review on this topic).

Thanks to studies performed by using these animal models, new therapeutic agents for NP management have been discovered, shedding a light on the possibilities for translating these new approaches to clinical practice.

Indeed, NP is extremely difficult to treat because it is a very complex disease with several mechanisms involved in the generation, propagation, as well as maintenance and enhancement of the stimulus through a central and/or peripheral pain processing.

Epigallocatechin-3-gallate (EGCG), the most abundant and active component of green tea, has multiple biological activities. Thus, it is considered as a compound with potential therapeutic effects in many diseases, including cancer. ${ }^{9}$ Several preclinical studies have shown that EGCG is involved in the regulation of different molecular signaling pathways by inhibiting the inflammation ${ }^{10,11}$ and by modulating the oxidative stress, processes directly connected to tumorigenesis. Importantly, emerging roles for EGCG have been also described in tumor microenvironment's modulation. ${ }^{12-14}$

In order to understand the role of EGCG in NP, we carried out a bibliographic research on the principal databases (PubMed and Embase) of the articles reported in the literature, in the last decade, regarding the effects of EGCG in animal model NPs. With this approach, we identified and included interesting research articles $(n=10)$ on the specified topic in the present review. Data from these studies showed that EGCG has antinociceptive effects due to its anti-inflammatory ${ }^{15,16}$ and antioxidant properties. ${ }^{16-18}$ Moreover, it has been reported that novel EGCG derivatives are able to modulate NP by decreasing the nuclear levels of nuclear factor kappa-light-chain-enhancer of activated B cells (NF- $\mathrm{kB}$ ) and the synthesis of proinflammatory cytokines such as interleukin 1 beta (IL-1 $\beta$ ) and tumor necrosis factor-alpha (TNF- $\alpha$ ). Recently, it has been reported that EGCG is able to reduce the pain due to bone cancer. ${ }^{19}$

In order to dissect the underlying molecular mechanisms and elucidate the therapeutic potential of EGCG in the treatment of NP, we summarize the preclinical studies reported in the literature.

\section{EGCG: a natural compound with multiple biological functions}

It has been shown that $30 \%$ of the weight of the plant $C$. sinensis is composed of EGCG. ${ }^{20}$ Belonging to the family of catechins, EGCG has redox activities since it is able to reduce reactive oxygen species (ROS). ${ }^{21,22}$ Moreover, this natural compound is subjected to many biological transformations and binds to target proteins and enzymes involved in the regulation of several molecular complex signaling pathways. ${ }^{9}$ Due to its multiple biological functions, several preclinical studies have been conducted during these years using EGCG in different types of diseases. Data from these experimentations established that EGCG is a chemopreventive and chemotherapeutic agent ${ }^{23}$ since it is able to modulate many pathological conditions (eg, cancer, ${ }^{9,24}$ inflammation, ${ }^{25,26,31}$ diabetes, ${ }^{27}$ neurodegenerative disorders, ${ }^{28,29,32}$ liver disease, ${ }^{30}$ and metabolic syndrome ${ }^{27}$ ). The most relevant properties of EGCG are summarized in Table 1.

In contrast to preclinical studies, data from epidemiological investigations based on the use of EGCG in the prevention of cancer in humans were not enthusiastic and lacked consistency, probably due to several factors (eg, genetic profile and lifestyle factors) interfering with the human's response to EGCG's treatment. ${ }^{33-35}$ Similarly, no 
Table I Principal biological activities of EGCG

\begin{tabular}{lll}
\hline Chemical structure & Properties & References \\
\hline EGCG & $\begin{array}{l}\text { Antioxidant } \\
\text { Anti-inflammatory }\end{array}$ \\
Antitumor-progression & 23 \\
Iron-chelating & 93
\end{tabular}

Abbreviation: EGCG, epigallocatechin-3-gallate.

encouraging results were obtained in human interventional trials conducted with EGCG in cancer patients. ${ }^{36-42}$ To date, few human investigations with the use of EGCG have been completed in other pathologies (eg, cystic fibrosis, ${ }^{43}$ Down syndrome,${ }^{44}$ and multiple sclerosis ${ }^{45}$ ) and no clinical trials have been conducted so far in patients suffering from NP. Thus, adequate and well-designed clinical studies aiming to improve the quantification of EGCG consumption in humans are needed.

\section{The effects of EGCG on NP: an overview of in vivo studies}

Thanks to the establishment of animal models of pain, it has been proved that EGCG has protective effects on pain or neuronal injuries, such as thermal hyperalgesia, peripheral nerve damage, and diabetic neuropathy. ${ }^{16,17,46-54}$ The first study on the effect of EGCG on NP was reported in 2012, by Kuang et al. ${ }^{16}$ The authors showed that NP induced by chronic constriction injury (CCI) of the rat sciatic nerve was reduced after intrathecal injection of EGCG $(1 \mathrm{mg} / \mathrm{kg})$ through the inhibition of Toll-like receptor 4 (TLR4)/NF- $\kappa B$ pathway. Similar findings were described by Choi et al. ${ }^{17}$ The authors demonstrated that EGCG displayed an antiallodynic effect against spinal nerve ligation (SNL)-induced NP through the inhibition of the nitric oxide (NO) and neuronal nitric oxide synthase (nNOS) protein expression. It should be noted that allodynia is a form of pain induced by a stimulus that normally is not able to provoke pain. Thus, an antiallodynic effect reduces this type of pain. Renno et $a{ }^{47}$ provided evidence that EGCG treatment in rats with impairment of skeletal muscle generated by peripheral nerve crush injury restores the morphology and the functionality of skeletal muscle, by activating antiapoptotic signaling pathway (Bax, $\mathrm{Bcl}-2$, and $\mathrm{p} 53$ proteins). Interestingly, Chen et $\mathrm{al}^{48}$ reported that EGCG was able to reduce adenomyosis and improve generalized hyperalgesia by reducing the expression of $\mathrm{p}-\mathrm{p} 65$, cyclooxygenase 2 (COX-2), oxytocin receptor (OTR), collagen I and IV, and transient receptor potential vanilloid type (TRPV1) in ectopic endometrium or myometrium. An et al ${ }^{49}$ reported an antiallodynic effect of EGCG in a neuropathic rat model induced by SNL. Data showed that EGCG modulated NP by attenuating ROS activity at the spinal level and inhibiting the expression level of xanthine oxidase (XO) and malondialdehyde (MDA). Another interesting study, conducted by Kurupova et al, reported the therapeutic potential of EGCG in the treatment of chronic fatigue syndrome. ${ }^{50}$ The authors provided evidence that EGCG significantly inhibited the expression of proinflammatory mediators and matrix metalloproteinases in vitro system (human intervertebral disc [IVD] cells), as well as radiculopathic pain in vivo, by modulating the activity of interleukin (IL)-1 receptorassociated kinases (IRAK-1) and its downstream effectors p38, c-Jun N-terminal kinases (JNK), and NF- $\kappa B$. Different data were described in a study conducted on streptozotocin (STZ)-diabetic rats..$^{51}$ The authors demonstrated that EGCG was able to reduce diabetic hyperalgesia induced by STZ by regulating the expression of 8-hydroxy-2'-deoxyguanosine (8-OHdG), a marker for oxidative damage, and of the nociceptive neuronal activation (Fos). The antinociceptive effects of EGCG and two of its polyphenolic derivatives, namely compounds 23 and 30, were also described in a mouse model of NP induced by CCI. ${ }^{46}$ Finally, in a recent paper, Bosch-Mola et al ${ }^{52}$ demonstrated that EGCG reduced thermal hyperalgesia by downregulating the expression of chemokine fractalkine ligand 1 (CX3CL1). Interestingly, for the first time, a role of EGCG in the modulation of NP caused by bone cancer, by acting on TNF- $\alpha$ signaling has been reported. ${ }^{19}$ Data from this study are very important and need to be potentiated, since bone cancer pain dramatically impairs patient's quality of life..$^{53,54}$ Table 2 summarizes the preclinical results described above.

\section{Molecular mechanisms underlying the NP's regulation mediated by EGCG}

Based on data emerged from in vivo studies described in the previous section, EGCG is able to inhibit NP through the modulation of the expression levels of key proteins involved in specific molecular pathways: 1) nNOS/NO; 2) CX3CL1, JNK, and NF-KB; and 3) TNF- $\alpha$. As represented in Figure 2, allodynia is reduced by EGCG which interferes with NO by inhibiting the nNOS/NO pathway. ${ }^{17}$ Chronic thermal hyperalgesia is attenuated by EGCG through the modulation of 
Table 2 Preclinical in vivo studies on the roles of EGCG in NP

\begin{tabular}{|c|c|c|c|c|c|}
\hline $\begin{array}{l}\text { Animal } \\
\text { models }\end{array}$ & $\begin{array}{l}\text { Dose of EGCG } \\
\text { drugs }\end{array}$ & Time of treatment & Principle of injuries & Effects & References \\
\hline Rat & I mg/kg, IT & $\begin{array}{l}\text { Once daily from I day before } \\
\text { to } 3 \text { days after } \mathrm{CCl}\end{array}$ & $\mathrm{CCl}$ & Inhibition of TLR4/NF-KB & 16 \\
\hline Rat & $\mathrm{I}, 3, \mathrm{I0}$, and $30 \mu \mathrm{g}$, IT & $5-60$ minutes after injection & SNL & $\begin{array}{l}\text { Attenuation of allodynia through } \\
\text { inhibition of nNOS protein } \\
\text { expression and inhibition of the } \\
\text { pronociceptive effects of NO }\end{array}$ & 17 \\
\hline Mouse & $\begin{array}{l}10,25,50 \text {, and } \\
100 \mathrm{mg} / \mathrm{kg}, \mathrm{IP}\end{array}$ & $\begin{array}{l}\text { Daily injections after } \\
\text { the intrafemoral tumor } \\
\text { inoculation }\end{array}$ & & $\begin{array}{l}\text { Reduction of pain behavior } \\
\text { through the inhibition of TNF- } \alpha \\
\text { pathways }\end{array}$ & 19 \\
\hline Rat & $50 \mathrm{mg} / \mathrm{kg}, \mathrm{IP}$ & $\begin{array}{l}\text { I hour after surgery followed } \\
\text { by adding two more injections } \\
\text { on days I and } 2 \text { post-surgery }\end{array}$ & SNL & $\begin{array}{l}\text { Improvement of morphological } \\
\text { recovery in skeletal muscle } \\
\text { after nerve injuries, by activating } \\
\text { antiapoptotic signaling pathway } \\
\text { (Bax/Bcl-2 and p53 protein) }\end{array}$ & 47 \\
\hline Mouse & $\begin{array}{l}5 \mathrm{mg} / \mathrm{kg} \text { body (low } \\
\text { dose); } 50 \mathrm{mg} / \mathrm{kg} \text { body } \\
\text { (high dose), IT }\end{array}$ & $\mathrm{I}-3$ weeks & $\begin{array}{l}\text { Adenomyosis induced } \\
\text { by oral administration } \\
\text { of tamoxifen }(1 \mathrm{mg} / \mathrm{kg})\end{array}$ & $\begin{array}{l}\text { Reduction of adenomyosis and } \\
\text { improvement of hyperalgesia by } \\
\text { reducing the expression of p-p65, } \\
\text { COX2, OTR, and collagen I/IV }\end{array}$ & 48 \\
\hline Rat & I, 3 , and $10 \mu \mathrm{g}$, IT & I-10 days post-surgery & SNL & $\begin{array}{l}\text { Inhibition of ROS activity and } \\
\text { reduction of the levels of XO } \\
\text { and MDA }\end{array}$ & 49 \\
\hline Rat & $10-100 \mu \mathrm{M}, \mathrm{OG}$ & I day post-surgery & SNL & $\begin{array}{l}\text { Reduction of pain perception by } \\
\text { modulating the activity of IRAK-I } \\
\text { and its downstream effectors } \\
\mathrm{p} 38 \text {, JNK, and NF-KB }\end{array}$ & 50 \\
\hline Rat & $2 \mathrm{~g} / \mathrm{L}, \mathrm{OG}$ & 10 weeks & $\begin{array}{l}\text { STZ-induced diabetic } \\
\text { NP }\end{array}$ & $\begin{array}{l}\text { Reduction of diabetic NP by } \\
\text { restoring the levels of } 8-O H d G \\
\text { and Fos }\end{array}$ & 51 \\
\hline Mouse & $\begin{array}{l}\text { EGCG and compounds } \\
23 \text { and } 30(10-100 \\
m g / k g, I P)\end{array}$ & $\begin{array}{l}\text { Daily during the first week } \\
\text { post-CCI }\end{array}$ & $\mathrm{CCl}$ & $\begin{array}{l}\text { Reduction of chronic thermal } \\
\text { hyperalgesia by reduction of } \\
\text { nuclear localization of NF-KB }\end{array}$ & 46 \\
\hline Mouse & $50 \mathrm{mg} / \mathrm{kg}, \mathrm{IP}$ & $\begin{array}{l}\text { Once a day during the first } \\
\text { week post-surgery }\end{array}$ & $\mathrm{CCl}$ & $\begin{array}{l}\text { Reduction of thermal hyperalgesia } \\
\text { by reduction of } \mathrm{C} \times 3 \mathrm{CLI}\end{array}$ & 52 \\
\hline
\end{tabular}

Abbreviations: 8-OHdG, 8-hydroxy-2'-deoxyguanosine; $\mathrm{CCl}$, chronic constriction injury of the sciatic nerve; COX2, cyclooxygenase 2; CX3CLI, chemokine fractalkine ligand I; EGCG, epigallocatechin-3-gallate; Fos, nociceptive neuron activation; IP, intraperitoneally; IRAK-I, interleukin (IL)-I receptor-associated kinases; IT, intrathecal; JNK, jun N-terminal kinases; MDA, malondialdehyde; NF- KB, nuclear factor kappa-light-chain-enhancer of activated B cells; nNOS, neuronal nitric oxide synthase; NO, nitric oxide; NP, neuropathic pain; OG, oral gavage; OTR, oxytocin receptor; ROS, reactive oxygen species; SNL, spinal nerve ligation; STZ, streptozotocin; TLR4, tolllike receptor 4 signaling pathway; TNF- $\alpha$, transcriptor nuclear factor- $\alpha$; XO, xanthine oxidase.

the expression levels of CX3CL1, ${ }^{52}$ which plays an important role in mediating the communication between neurons and microglia. Hyperalgesia and the reduction of pain perception are reduced by EGCG through the modulation of JNK and NF- $\kappa$ B activities. ${ }^{52}$ Bone cancer-related pain, which dramatically impairs the patient's quality of life, is attenuated by $\mathrm{EGCG}^{19}$ through the inhibition of TNF- $\alpha$ pathway.

\section{Concluding remarks and future perspectives}

Due to the lack of efficacy of therapies for NP treatment, new alternative approaches have been tested in preclinical study, by using animal models of NP treated with EGCG. Interesting results obtained from these in vivo studies proved that EGCG is able to ameliorate NP by acting on different molecular signaling pathways. Furthermore, a role of EGCG for the treatment of pain from bone metastases has also been proposed. Despite these encouraging preclinical results, no clinical trials have been performed using EGCG in patients suffering from NP. For these reasons, more studies are needed to translate the use of EGCG into clinical practice for management of NP. These studies should be addressed 1) to better understand the pathogenesis of NP; 2) to identify the optimal animal models of NP (central pain models, drug-induced neuropathy models, disease-induced neuropathy models) in order to dissect the mechanisms regulated by EGCG in NP; and 3) to identify the optimum therapeutic dosage of EGCG for intervention trials in patients suffering from NP. 


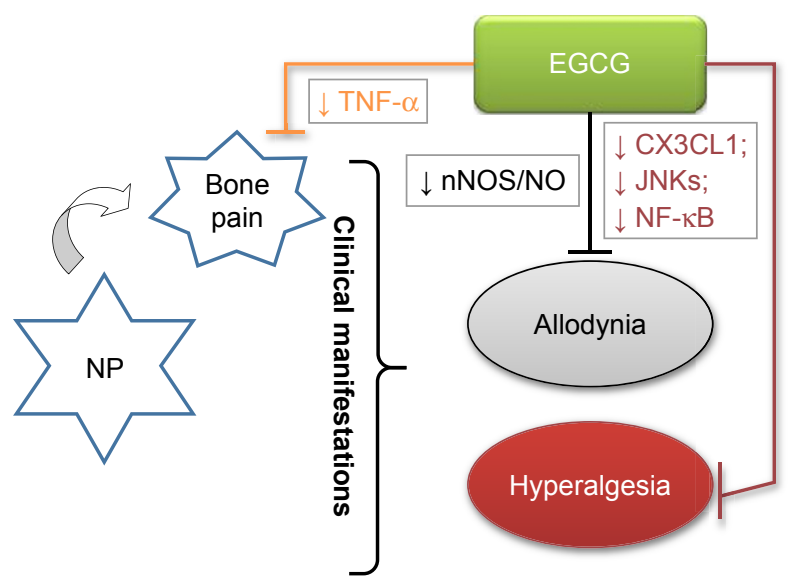

Figure 2 Principal signaling pathways regulated by EGCG in NP.

Notes: EGCG is able to modulate different types of NP by downregulating the expression levels of NF- $\kappa B$, JNKs, nNOS/NO, CX $3 \mathrm{CLI}$, and TNF- $\alpha$ proteins. The arrows indicate downregulation.

Abbreviations: $\mathrm{CX} 3 \mathrm{CLI}$, chemokine fractalkine ligand; EGCG, epigallocatechin3-gallate; JNKs, c-Jun N-terminal kinases; NF- $\mathrm{BB}$, nuclear factor kappa-light-chainenhancer of activated $\mathrm{B}$ cells; nNOS, neuronal nitric oxide synthase; NO, nitric oxide; NP, neuropathic pain; TNF- $\alpha$, tumor necrosis factor- $\alpha$.

\section{Acknowledgments}

We are grateful to Dr Alessandra Trocino and Mrs Cristina Romano from the National Cancer Institute of Naples for providing excellent bibliographic service and assistance.

\section{Author contributions}

The present review was mainly written by SB and MC. All authors contributed toward data analysis, drafting and critically revising the paper, gave final approval of the version to be published, and agree to be accountable for all aspects of the work.

\section{Disclosure}

The authors report no conflicts of interest in this work.

\section{References}

1. Jensen TS, Baron R, Haanpaa M, et al. A new definition of neuropathic pain. Pain. 2011;152(10):2204-2205.

2. Woolf CJ, Mannion RJ. Neuropathic pain: aetiology, symptoms, mechanisms, and management. Lancet. 1999;353(9168):1959-1964.

3. Torrance N, Smith BH, Bennett MI, Lee AJ. The epidemiology of chronic pain of predominantly neuropathic origin. Results from a general population survey. J Pain. 2006;7(4):281-289.

4. Dworkin RH, Backonja M, Rowbotham MC, et al. Advances in neuropathic pain: diagnosis, mechanisms, and treatment recommendations. Arch Neurol. 2003;60(11):1524-1534.

5. Bouhassira D, Lanteri-Minet M, Attal N, Laurent B, Touboul C. Prevalence of chronic pain with neuropathic characteristics in the general population. Pain. 2008;136(3):380-387.

6. Cascella M, Muzio MR, Viscardi D, Cuomo A. Features and role of minimally invasive palliative procedures for pain management in malignant pelvic diseases: a review. Am J Hosp Palliat Care. 2017;34(6):524-531.

7. Wolf CJ, Ostby JS, Gray LE Jr. Gestational exposure to 2,3,7, 8-tetrachlorodibenzo-p-dioxin (TCDD) severely alters reproductive function of female hamster offspring. Toxicol Sci. 1999;51(2):259-264.
8. Jaggi AS, Jain V, Singh N. Animal models of neuropathic pain. Fundam Clin Pharmacol. 2011;25(1):1-28.

9. Yang CS, Wang H. Cancer preventive activities of tea catechins. Molecules. 2016;21(12):E1679.

10. Syed DN, Afaq F, Kweon MH, et al. Green tea polyphenol EGCG suppresses cigarette smoke condensate-induced NF-kappaB activation in normal human bronchial epithelial cells. Oncogene. 2007; 26(5):673-682.

11. Pan H, Chen J, Shen K, et al. Mitochondrial modulation by epigallocatechin 3-gallate ameliorates cisplatin induced renal injury through decreasing oxidative/nitrative stress, inflammation and NF-kB in mice. PLoS One. 2015;10(4):e0124775.

12. Deng PB, Hu CP, Xiong Z, Yang HP, Li YY. Treatment with EGCG in NSCLC leads to decreasing interstitial fluid pressure and hypoxia to improve chemotherapy efficacy through rebalance of Ang-1 and Ang-2. Chin J Nat Med. 2013;11(3):245-253.

13. Jang JY, Lee JK, Jeon YK, Kim CW. Exosome derived from epigallocatechin gallate treated breast cancer cells suppresses tumor growth by inhibiting tumor-associated macrophage infiltration and M2 polarization. BMC Cancer. 2013;13:421.

14. Gray AL, Stephens CA, Bigelow RL, Coleman DT, Cardelli JA. The polyphenols (-)-epigallocatechin-3-gallate and luteolin synergistically inhibit TGF-beta-induced myofibroblast phenotypes through RhoA and ERK inhibition. PLoS One. 2014;9(10):e109208.

15. Khalatbary AR, Ahmadvand H. Anti-inflammatory effect of the epigallocatechin gallate following spinal cord trauma in rat. Iran Biomed $J$. 2011;15(1-2):31-37.

16. Kuang X, Huang Y, Gu HF, et al. Effects of intrathecal epigallocatechin gallate, an inhibitor of Toll-like receptor 4, on chronic neuropathic pain in rats. Eur J Pharmacol. 2012;676(1-3):51-56.

17. Choi JI, Kim WM, Lee HG, Kim YO, Yoon MH. Role of neuronal nitric oxide synthase in the antiallodynic effects of intrathecal EGCG in a neuropathic pain rat model. Neurosci Lett. 2012;510(1):53-57.

18. Wei IH, Tu HC, Huang CC, Tsai MH, Tseng CY, Shieh JY. (-)-Epigallocatechin gallate attenuates NADPH-d/nNOS expression in motor neurons of rats following peripheral nerve injury. BMC Neurosci. 2011;12:52.

19. Li Q, Zhang X. Epigallocatechin-3-gallate attenuates bone cancer pain involving decreasing spinal tumor necrosis factor-alpha expression in a mouse model. Int Immunopharmacol. 2015;29(2):818-823.

20. Graham HN. Green tea composition, consumption, and polyphenol chemistry. Prev Med. 1992;21(3):334-350.

21. Sang S, Lambert JD, Ho CT, Yang CS. The chemistry and biotransformation of tea constituents. Pharmacol Res. 2011;64(2):87-99.

22. Dickinson BC, Chang CJ. Chemistry and biology of reactive oxygen species in signaling or stress responses. Nat Chem Biol. 2011;7(8): 504-511.

23. Zubair H, Azim S, Ahmad A, et al. Cancer chemoprevention by phytochemicals: nature's healing touch. Molecules. 2017;22(3):E395.

24. Bimonte S, Leongito M, Barbieri A, et al. Inhibitory effect of (-)epigallocatechin-3-gallate and bleomycin on human pancreatic cancer MiaPaca-2 cell growth. Infect Agent Cancer. 2015;10:22.

25. Fajardo AM, Piazza GA. Chemoprevention in gastrointestinal physiology and disease. Anti-inflammatory approaches for colorectal cancer chemoprevention. Am J Physiol Gastrointest Liver Physiol. 2015;309(2):G59-G70.

26. Riegsecker S, Wiczynski D, Kaplan MJ, Ahmed S. Potential benefits of green tea polyphenol EGCG in the prevention and treatment of vascular inflammation in rheumatoid arthritis. Life Sci. 2013;93(8):307-312.

27. Legeay S, Rodier M, Fillon L, Faure S, Clere N. Epigallocatechin gallate: a review of Its beneficial properties to prevent metabolic syndrome. Nutrients. 2015;7(7):5443-5468.

28. Chakrawarti L, Agrawal R, Dang S, Gupta S, Gabrani R. Therapeutic effects of EGCG: a patent review. Expert Opin Ther Pat. 2016;26(8):907-916.

29. Xu L, Tu S, Chen C, Zhao J, Zhang Y, Zhou P. Effect of EGCG on Fe(III)induced conformational transition of silk fibroin, a model of protein related to neurodegenerative diseases. Biopolymers. Epub 2015 Oct 16. 
30. Song HU, Hwang SG. [Prevention of hepatocellular carcinoma]. Korean J Gastroenterol. 2007;49(4):201-208. Korean.

31. Oz HS. Chronic inflammatory diseases and green tea polyphenols. Nutrients. 2017;9(6):E561.

32. Mandel SA, Amit T, Kalfon L, Reznichenko L, Weinreb O, Youdim MB. Cell signaling pathways and iron chelation in the neurorestorative activity of green tea polyphenols: special reference to epigallocatechin gallate (EGCG). J Alzheimers Dis. 2008;15(2):211-222.

33. Gao YT, McLaughlin JK, Blot WJ, Ji BT, Dai Q, Fraumeni JF Jr. Reduced risk of esophageal cancer associated with green tea consumption. J Natl Cancer Inst. 1994;86(11):855-858.

34. Sasazuki S, Tamakoshi A, Matsuo K, et al. Green tea consumption and gastric cancer risk: an evaluation based on a systematic review of epidemiologic evidence among the Japanese population. Jpn J Clin Oncol. 2012;42(4):335-346.

35. Li N, Sun Z, Han C, Chen J. The chemopreventive effects of tea on human oral precancerous mucosa lesions. Proc Soc Exp Biol Med. 1999;220(4):218-224.

36. Tsao AS, Liu D, Martin J, et al. Phase II randomized, placebo-controlled trial of green tea extract in patients with high-risk oral premalignant lesions. Cancer Prev Res (Phila). 2009;2(11):931-941.

37. Shimizu M, Fukutomi Y, Ninomiya M, et al. Green tea extracts for the prevention of metachronous colorectal adenomas: a pilot study. Cancer Epidemiol Biomarkers Prev. 2008;17(11):3020-3025.

38. Bettuzzi S, Brausi M, Rizzi F, Castagnetti G, Peracchia G, Corti A. Chemoprevention of human prostate cancer by oral administration of green tea catechins in volunteers with high-grade prostate intraepithelial neoplasia: a preliminary report from a one-year proof-of-principle study. Cancer Res. 2006;66(2):1234-1240.

39. Crew KD, Brown P, Greenlee H, et al. Phase IB randomized, doubleblinded, placebo-controlled, dose escalation study of polyphenon $\mathrm{E}$ in women with hormone receptor-negative breast cancer. Cancer Prev Res (Phila). 2012;5(9):1144-1154.

40. Kumar NB, Pow-Sang J, Egan KM, et al. Randomized, placebocontrolled trial of green tea catechins for prostate cancer prevention. Cancer Prev Res (Phila). 2015;8(10):879-887.

41. Joe AK, Schnoll-Sussman F, Bresalier RS, et al. Phase Ib randomized, double-blinded, placebo-controlled, dose escalation study of polyphenon E in patients with Barrett's esophagus. Cancer Prev Res (Phila). 2015;8(12):1131-1137.

42. Shanafelt TD, Call TG, Zent CS, et al. Phase 2 trial of daily, oral polyphenon $\mathrm{E}$ in patients with asymptomatic, Rai stage 0 to II chronic lymphocytic leukemia. Cancer. 2013;119(2):363-370.
43. De Stefano D, Villella VR, Esposito S, et al. Restoration of CFTR function in patients with cystic fibrosis carrying the F508del-CFTR mutation. Autophagy. 2014;10(11):2053-2074.

44. de la Torre R, de Sola S, Hernandez G, et al. Safety and efficacy of cognitive training plus epigallocatechin-3-gallate in young adults with down's syndrome (TESDAD): a double-blind, randomised, placebocontrolled, phase 2 trial. Lancet Neurol. 2016;15(8):801-810.

45. Mahler A, Steiniger J, Bock M, et al. Metabolic response to epigallocatechin-3-gallate in relapsing-remitting multiple sclerosis: a randomized clinical trial. Am J Clin Nutr. 2015;101(3):487-495.

46. Xifro X, Vidal-Sancho L, Boadas-Vaello P, et al. Novel epigallocatechin3-gallate (EGCG) derivative as a new therapeutic strategy for reducing neuropathic pain after chronic constriction nerve injury in mice. PLoS One. 2015;10(4): 0123122.

47. Renno WM, Al-Maghrebi M, Al-Banaw A. (-)-Epigallocatechin3-gallate (EGCG) attenuates functional deficits and morphological alterations by diminishing apoptotic gene overexpression in skeletal muscles after sciatic nerve crush injury. Naunyn Schmiedebergs Arch Pharmacol. 2012;385(8):807-822.

48. Chen Y, Zhu B, Zhang H, Ding D, Liu X, Guo SW. Possible loss of GABAergic inhibition in mice with induced adenomyosis and treatment with epigallocatechin-3-gallate attenuates the loss with improved hyperalgesia. Reprod Sci. 2014;21(7):869-882.

49. An SS, Kim YO, Park CH, Lin H, Yoon MH. Antiallodynic effect of intrathecal epigallocatechin-3-gallate due to suppression of reactive oxygen species. Korean J Anesthesiol. 2014;67(2):123-128.

50. Krupkova O, Sekiguchi M, Klasen J, et al. Epigallocatechin 3-gallate suppresses interleukin-1beta-induced inflammatory responses in intervertebral disc cells in vitro and reduces radiculopathic pain in rats. Eur Cell Mater. 2014;28:372-386.

51. Raposo D, Morgado C, Pereira-Terra P, Tavares I. Nociceptive spinal cord neurons of laminae I-III exhibit oxidative stress damage during diabetic neuropathy which is prevented by early antioxidant treatment with epigallocatechin-gallate (EGCG). Brain Res Bull. 2015;110:68-75.

52. Bosch-Mola M, Homs J, Alvarez-Perez B, et al. (-)-Epigallocatechin3-gallate antihyperalgesic effect associates with reduced CX3CL1 chemokine expression in spinal cord. Phytother Res. 2017;31(2): 340-344.

53. [No authors listed]. Skeletal complications of malignancy. Proceedings of a symposium. Bethesda, Maryland, April 19-20, 1997. Cancer. 1997;80(8 Suppl):1527-1701.

54. Coleman RE. Metastatic bone disease: clinical features, pathophysiology and treatment strategies. Cancer Treat Rev. 2001;27(3):165-176.
Drug Design, Development and Therapy

\section{Publish your work in this journal}

Drug Design, Development and Therapy is an international, peerreviewed open-access journal that spans the spectrum of drug design and development through to clinical applications. Clinical outcomes, patient safety, and programs for the development and effective, safe, and sustained use of medicines are the features of the journal, which

\section{Dovepress}

has also been accepted for indexing on PubMed Central. The manuscript management system is completely online and includes a very quick and fair peer-review system, which is all easy to use. Visit http://www.dovepress.com/testimonials.php to read real quotes from published authors. 